\title{
SEED PROTEIN, OIL, AND YIELD OF SOYBEAN GENOTYPES WITH HIGH AND NORMAL OLEIC ACID CONCENTRATION
}

THANG CAO LA

\author{
Dr. J. Grover Shannon, Thesis Supervior
}

\begin{abstract}
Soybeans with seed oil high in oleic acid content have been developed and are desired by oil processors because of improved oxidative stability for broader use in food, fuel and other products. Conventional soybean lines with $80 \%$ oleic acid content were generated by combining two mutant genes, mutant S117N FAD2-1A allele from 17D and mutant P137R FAD2-1B allele from PI283327. Thirty five F4:7 high oleic lines with these mutant FAD2-1A and FAD2-1B genes were compared to thirty five F4:7 normal or wild type oleic acid lines for seed contents of the five fatty acids common to soybean, total oil content, total protein content, and seed yield from five crosses grown in six environments. The high oleic genotypes averaged $>75 \%$ oleic acid content and concentrations of palmitic and linolenic acids were significantly lower (30\% lower) than their normal oleic acid counterparts in each environment. When averaged across all locations and populations, seed yield of the high oleic lines were within $2 \%$ of the normal oleic lines. Because of the negative correlation of protein with oil content and seed yield shown in many other studies, it was surprising that these high oleic lines averaged significantly higher in protein and oil with similar yield compared to normal oleic lines. These results provided evidence that high oleic soybeans can have comparable yields with the potential to generate more oil with greater functionality and higher protein meal for improved feed and food value compared to soybeans with normal oleic acid content from the same cross.
\end{abstract}

